\title{
From peri-implantitis to dental emergency - minor, medium, major?
}

\author{
Ilinca Ana LAZAR ${ }^{1}$, Augustin MIHAl ${ }^{1}$, Gabriela TANASE ${ }^{1}$, Mihai BURLIBASA ${ }^{1}$, \\ Corina Marilena CRISTACHE ${ }^{1}$, Viorel PERIEANU ${ }^{1}$, Mădălina PERIEANU ${ }^{1}$, Luminita OANCEA ${ }^{1}$, \\ Liliana BURLIBASA ${ }^{2}$, Ileana IONESCU ${ }^{1}$, Constantin Florin DRAGAN ${ }^{1}$, Oana EFTENE ${ }^{1}$, \\ Iuliana BABIUC ${ }^{1}$, Claudia-Camelia BURCEA ${ }^{1}$, Liliana MORARU ${ }^{3}$ \\ 1 "Carol Davila" University of Medicine and Pharmacy, Bucharest, Romania \\ ${ }^{2}$ Faculty of Biology, University of Bucharest, Romania \\ 3 "Titu Maiorescu" University, Bucharest, Romania
}

\begin{abstract}
Introduction. Peri-implantitis is a condition of the tissues adjacent to dental implants, which can occur in patients with implant-prosthetic restorations, following inadequate prophylactic measures. However, these peri-implants, untreated or improperly treated, can lead over time to quite severe complications, which can quickly turn into emergencies of low, medium or increased intensity in the usual dental care.

Purpose. Peri-implantitis is not a major dental emergency, but ignoring and/or treating it incorrectly can lead to complications that are considered major in dentistry. That is why we tried through this study to verify the knowledge related to peri-implantitis as well as the complications that may arise from the nontreatment of these diseases, among the practitioners involved in this field.

Material and method. The study was conducted with the help of 37 specialists involved in implantprosthetic treatments, aged between 37 and 53 years, using a 7-point questionnaire.

Results and discussions. The results show the concern of specialists in the field of oral implantology regarding peri-implantitis, as well as the complications arising from them.

Conclusions. Knowing the causes but also the complications arising from peri-implantitis are very important for the creating preventive programs, which with a reduced effort bring the long-term success of implant supported restorations.
\end{abstract}

Keywords: peri-implant diseases, peri-implantitis, dental emergencies

\section{INTRODUCTION}

The "osseointegration" concept, well defined by the renowned Prof. Per-Ingvar Bränemark, considered, along with Carl Mish, to be one of the creators of modern implantology, as well as the emergence of the cylindrical design of dental implants, revolutionized den- tal treatment, replacement of missing teeth with the help of implants being an important part in contemporary dentistry (1).

Extremely numerous researches from the last 3 and a half decades have confirmed the success of osseointegrated implants, as an alternative of dental treat- 
ment, in the case of edentulous spaces from one tooth to all teeth (1).

Despite the development of materials and the emergence of new techniques, which ensure a high degree of clinical success, the long-term success of dental implants is dependent on the efforts of both the patient and the dental team, which deals with its implant-prosthetic rehabilitation in maintaining the health of peri-implant tissues: the surgeon (specialist in dento-alveolar surgery and/or oral and maxillo-facial surgery, or a dentist with graduate of advanced courses in the field of oral implantology, the specialist in dental prosthetics, the prophylaxis assistant and/or the dental hygienist (at the time of 2020, the profession of dental hygienist is not yet legislated in Romania) (1).

\section{PURPOSE}

As we mentioned in a previous material, during implant-prosthetic rehabilitation a series of complications can occur, which in time can even lead to the loss of the implant itself. Thus, these complications can be summarized as follows: accidents (intraoperative incidents); complications during the osseointegration period; accidents that may occur when mounting the prosthetic abutment and when fixing or cementing the prosthetic superstructure; late complications, which included both peri-implant mucositis and peri-implantitis (2).

If peri-implant mucositis is just a reversible inflammatory reaction of the mucosa adjacent to a dental implant, peri-implantitis is a much more serious, much more complex condition, in which case it is an inflammatory process of a microbial nature that affects the tissues around an osseointegrated, prosthetic loaded dental implant and which can cause loss of supporting bone tissue. Specifically, the loss of supporting bone tissue of a dental implant following an untreated and/or improperly treated peri-implant infectious process (peri-implantitis) can lead in shorter or longer periods to mobilization, followed by loss of the dental implant $(3,4)$.

Starting from this information previously presented, we tried in this material to show that peri-implantitis is not a major dental emergency, it can be prevented both by the care and conscientiousness of patients and by the professionalism of the medical team (dental implantologist, the prosthetic specialist, the dental prophylaxis nurse and/or the dental hygienist), but this major emergency in dentistry can be represented by the complications that can occur following peri-implantitis. In fact, these aspects are the purpose of this study, even if it is only of a preliminary nature.

\section{MATERIAL AND METHOD}

Before moving on to the description of the study, we will review the emergencies of the oral and maxil- lo-facial region, which are divided into two major categories (5-7). The first category is represented by the conditions which, in general, cannot be fully assisted in a regular state or private dental office. Even if, in this category of diseases, the dentist cannot provide complete assistance, he has the obligation both legally and morally to provide first aid and to know very well how the patient must reach the most competent medical service, to solve its problems. And here we discuss the real oral and maxillo-facial medical-surgical emergencies, such as: traumas (open or closed fractures), soft tissue wounds, as well as septic conditions caused by suppurations in different regions of the oral and maxillofacial region. The second category is represented by the conditions that can be fully assisted in a regular dental office or ambulatory dental care unit. In this category we also find surgical emergencies, which the dentist can completely treat. This category of diseases includes small and limited trauma, post-extraction bleeding, suppurations from periodontal pockets or in superficial areas, easily accessible. But to this category of diseases are added those which, due to an alarming symptom, the pain, cause today a very high frequency of emergency requests for a dental care, at any time of day or night and which are represented by acute pulpitis (5-7).

Next, we will focus on some aspects of peri-implantitis, the enumeration of some methods of their treatment, but also the evolution over time and the complications that may occur in case of non-treatment and/or improper treatment (8).

Preventive attitude is essential for the long-term success of dental implant treatment. Implant-prosthetic rehabilitated patients will need preventive care in several stages of treatment and later in the follow-up care process. The prevention of peri-implant diseases (here we refer mainly to peri-implantitis) must be an important objective for both the doctor and the patient. Equally important is the attention that must be paid to the correct care of the prosthetic superstructure, of the natural teeth existing on the arches, as well as of the possible classic prosthetic restorations (8).

Thus, in order to prevent the occurrence of peri-implantitis following implant-prosthetic rehabilitation, it is necessary to establish very rigorous prophylactic measures, which concern both the medical team (implant specialist, prosthetic specialist, dental prophylaxis assistant and/or dental hygienist), as well as patients.

This very important association between professional prophylactic care and personal care, as a whole, is the basic long-term criterion of treatment with dental implants. Basically, this association between the professional care of the medical team and the personal care of the patients is a basic element both in the prevention of peri-implant diseases such as peri-implanti- 
tis, and in the subsequent maintenance of implant-supported restorations (9).

The frequency of follow-up care examination is extremely important, along with the sequence of therapeutic stages and must be individualized for each patient, depending on needs, particularities and clinical evolution (9). The patient must be aware and motivated to present at regular check-ups, at time intervals established by the medical team, but also whenever he deems it necessary, at the appearance of any alarming sign/symptom (9). The professional measures applied in prophylactic care must take into account several factors, namely: the stage of treatment; type of implant and prosthetic restoration; the condition of the oral tissues; general health; the risk group in which the patient is placed (depending on the risk factors detected by anamnesis, clinical examination and paraclinical examinations) (9).

But when we discuss the classic clinical signs of peri-implantitis in implant-prosthetic rehabilitated patients, they can be described as follows (4): the presence of vertical destruction of the alveolar bone; formation of peri-implant pockets; edematous tissues; implant mobility; bleeding and/or suppuration on slight palpation etc.

In order to establish a correct diagnosis, in addition to a rigorous anamnesis, it is recommended to perform high quality imaging examinations (conventional radiography, orthopantomogram - OPG, digital radiography etc.), as well as a professional interpretation of them.

Regarding the methods of treatment for peri-implantitis, they vary from case to case and may consist of maneuvers to remove dental microbial plaque, associated with surgical methods (removal of damaged tissue, evacuation of purulent collections when necessary) and administration of local and/or general medicinal products such as anti-inflammatory, antimicrobial, antibiotic substances, etc. We will not be able to describe these treatment protocols in detail in the case of peri-implantitis in this article, but this will most likely be done in another material.

However, the complications that may occur in the case of incorrect or non-treatment of peri-implantitis in implant-prosthetic rehabilitated patients can also lead to extremely aggressive complications, in the category of those we consider to be major, medium or minor emergencies in dental care: suppurative processes of a greater or lesser extent in the oral and maxillo-facial region in the vicinity of dental implants, pain of different intensities, mobility of dental implants of varying degrees that can lead at their loss.

Starting from these considerations mentioned in the beginning of the paper and for conducting a very brief study, we developed a questionnaire with 7 points, applied to 37 dentists who are involved in the treatment of implant-prosthetic rehabilitation (both professionals who insert dental implants and prosthetic specialists). All practitioners included in the study are between 37 and 53 years old and work only in large cities in Romania: Bucharest, Brasov, Constanta, Sibiu, Rm. Valcea, Alexandria, Pitesti, Tg. Jiu, Craiova. The gender distribution of the subjects was as follows: 21 of the dental practitioners $(56.76 \%)$ were female and 16 subjects $(43.24 \%)$ were male (Fig. 1 ).

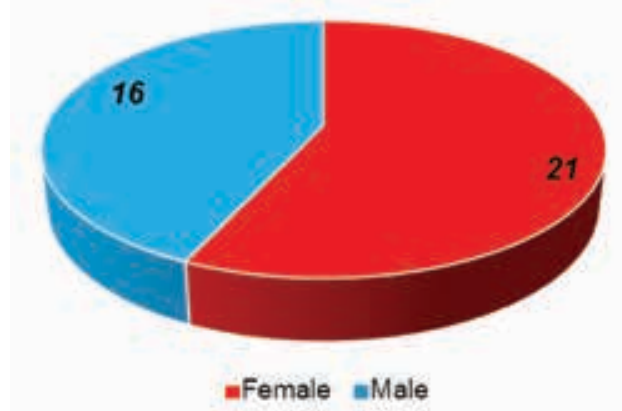

FIGURE 1. Gender distribution of the subjects involved in the study

The composition of the questionnaire is as follows:

\section{Questionnaire}

1. What is your attitude, as dentists, towards emergency dental care? a. Must be provided regardless of the patient; $\boldsymbol{b}$. Patients should be selected for emergency treatment. c. Patients must be selected according to their financial possibilities? Correct answer: a.

2. The prevention of peri-implant diseases such as peri-implantitis in the case of implant-prosthetic rehabilitated patients requires the establishment of rigorous prophylactic measures, which concern: $a$. Only the medical team; $b$. Only patients; $c$. Both the dental team and the patients. Correct answer: $\mathbf{c}$.

3. In the case of peri-implantitis, the frequency of regular medical check-ups, together with the sequence of therapeutic stages: $\boldsymbol{a}$. They are universal for every patient; $\boldsymbol{b}$. They must be individualized for each patient; c. They should be done selectively, depending on the financial possibilities of the patients? Correct answer: $\mathbf{b}$.

4. In the case of peri-implantitis in implant-prosthetic rehabilitated patients implanted, the following clinical signs may be described: $a$. Presence of vertical destruction of the alveolar bone; $\boldsymbol{b}$. Formation of peri-implant pockets; $c$. Edematous tissues; d. Implant mobility; e. Bleeding and/or suppuration on slight palpation. Correct answers: a, b, c, d, e.

5. Establishing a correct diagnosis, in the case of peri-implantitis in patients whit implant supported restorations, is made only on the basis of: $\boldsymbol{a}$. History and clinical symptoms; $\boldsymbol{b}$. Anamnesis and clinical symptoms, associated with high quality imaging examinations; $c$. Only on the basis of clinical symptoms. Correct answer: $\mathbf{b}$. 
6. In the category of complications following peri-implantitis in implant-prosthetic rehabilitated patients, there are: $\boldsymbol{a}$. Suppurative processes of a greater or lesser magnitude occurred in the oral and maxillo-facial region in the vicinity of dental implants; $\boldsymbol{b}$. Pain of different intensities in the oral and maxillo-facial region; c. Mobility of dental implants of varying degrees, which can lead to their loss; d. Irreversible loss of taste sensitivity; e. Major dysfunctions in the temporomandibular joint. Correct answers: a, b, c.

7. Which of the following conditions do you consider to be dental emergencies? a. Classical peri-implantitis; b. Complications following peri-implantitis such as suppurations of a greater or lesser extent occurred in the vicinity of dental implants and/or severe pain in the oral and maxillo-facial region; c. Hypersalivation; $\boldsymbol{d}$. Temporary paralysis in the oral and maxillo-facial region. Correct answer: $\mathbf{b}$.

\section{RESULTS}

As expected, all practitioners involved in the study considered that emergency dental care should be provided without discrimination.

About the prophylactic measures to prevent peri-implantitis, the majority of respondents (29 representing $78.38 \%$ ) considered that it is an action that must involve both the medical team and the patients. The rest of the respondents considered that this action targets either only the medical team ( 5 respondents) or only the patients (3 respondents) (Fig. 2).

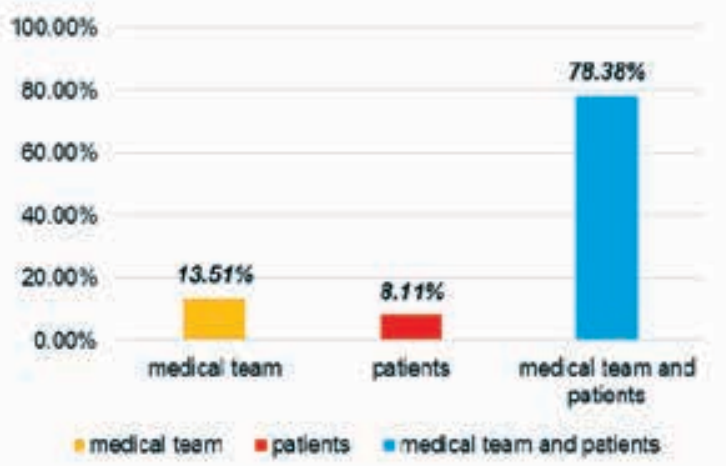

FIGURE 2. Involvement of the medical team and patients in the process of preventing peri-implantitis

The habit of using standard protocols in current practice made 11 of the respondents (representing $29.73 \%$ ) to consider that the therapeutic protocol in the case of peri-implantitis is identical for all patients. The majority of respondents ( 26 representing $70.27 \%$ ) correctly considered that follow-up care process of peri-implantitis requires an individualization regarding the frequency of recall intervals, but also of the therapeutic stages (Fig. 3).

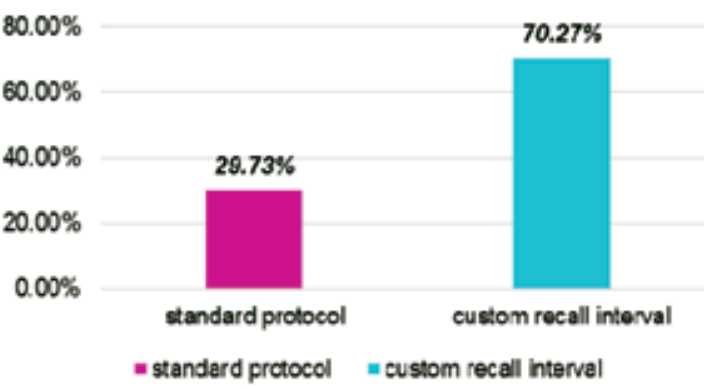

FIGURE 3. How to approach patients with peri-implantitis in the follow-up process

Regarding the clinical signs of peri-implantitis and the elements on the basis of which a correct diagnosis can be established, all participants in the study answered correctly.

The complications arising from ignoring or incorrectly treating the incipient forms of peri-implantitis are clearly understood by most of the specialists participating in the study (30 representing $81.08 \%$ ). Just a few specialists (7 representing $18.92 \%$ ) wrongly included in addition to the correct answers and major dysfunctions of the temporomandibular joint (Fig. 4).

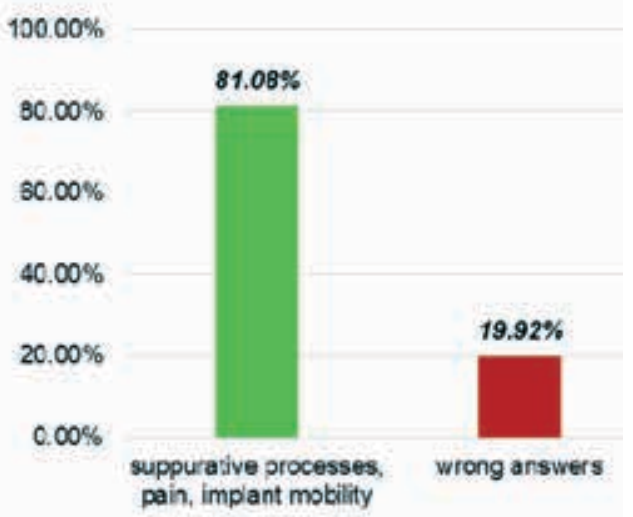

FIGURE 4. Knowledge of the complications following periimplantitis by the specialists included in the study

For the last question, related to dental emergencies, all respondents answered correctly, namely the septic complications arising from the uncontrolled evolution of peri-implantitis.

\section{DISCUSSIONS}

In 2017, in the World Workshop on the classification of periodontal and perio-implant diseases and conditions, it was concluded that the microbial factor plays an important role in the occurrence of peri-implantitis (10). This is supported by studies done before 2017. In 1992, Mombelli used antimicrobial treatment for peri-implant infections associated with a periodontitis-like subgingival microbiota (11). In 2011, Corbella conducting a study related to maintenance protocol for the prevention of peri-implant diseases, mentioned 
that it is necessary to establish a systematic hygienic protocol that has the effect of reducing the rate of peri-implantitis and control of microbial plaque in implants and prosthetic elements attached to it (12). Thus, the extension of the life of implant supported prosthetic restorations is mainly related to the degree of health of the tissues surrounding the implant. In the case of peri-implantitis, the treatment must have as main objective the control of the infection appeared at the interface between the implant and surrounding the tissues. In 2006, De Araujo Nobre in a study aimed at the non-surgical treatment of peri-implantitis, drew attention to 3 factors in obtaining a successful treatment: establishing an optimal diagnosis, removing etiological factors and most importantly good patient's oral hygiene self-care (13). In this way, both the medical team and the patient have an active role in preventing peri-implantitis.

Similarly, in addition to the therapeutic stages, the recall interval for patients with implant supported restoration is of particular importance. In 2015, Monje recommended, following a literature research, for recall a minimum interval of 5-6 months, but emphasized the customization of this interval according to the patient's risk profiling (14). Howe obtained similar conclusions in 2017 in a specialized review related to implant maintenance treatment, making the same connection between recall interval and risk profile of the patient (15).

The establishment of a correct diagnosis is made on the basis of clinical signs, on the examinations that the specialist doctor can make in order to establish the degree of health of the peri-implant tissues. In 2009, Lang mentioned that in diagnosing of peri-implantitis, parameters such as "bleeding on probing", "probing depths" and radiographic exams are more sensitive and reliable (16). In 2021, Romandini following an extensive study concluded that in most cases peri-implant diseases are asymptomatic and may go unnoticed especially by the patient, for this reason, examinations and measurements made by the doctor in recall visits could reveal different degrees of damage to peri-implant tissues from a simple mucositis to peri-implantitis (17).

Untreated dental infections can cause neighborhood septic complications in the maxillofacial region. Conflict of interest: none declared Financial support: none declared

\section{REFERENCES}

1. Cristache CM. Implant versus dinte natural In: Cristache CM, Tănase G, Burlibașa M. Progrese în medicina dentară (Vol. II). București: Ed. Ars Docendi, 2012:9-27.

2. Gănuță N, Bucur $A$, Gănuță $A$. Tratat de implantologie orală. București: Ed. Naţional, 1997.
Similarly, peri-implantitis, having a bacterial cause, can lead to similar complications, especially when the implant is in the vicinity of anatomical formations that can become inflamed and easily infected. One such case is described by Steiner in 2021, when a peri-implantitis from a dental implant placed in the upper jaw, came into contact with the floor of the maxillary sinus and later the infection spread to the frontal sinuses resulting in a brain abscess which proved to be fatal (18). That is why the complications must be well known by practitioners, and together with the patients in a joint effort to keep under control the health of the peri-implant tissues in order to avoid tragic situations.

Another complication of peri-implantitis is implant failure, but as Jemt shows in 2017, it is associated with the early inflammatory problems or with bad habits of the patients like smoking (19). Also, a peri-implantitis discovered late and which produced significant peri-implant bone loss can lead to the loss of the dental implant, a situation exemplified by Vanchit John in 2016 (20).

\section{CONCLUSIONS}

Peri-implantitis can often go unnoticed, which is why it is essential to establish a follow-up care program to monitor the health of peri-implant tissues.

The in-depth knowledge by the practitioner and through him further to the patient of the complications that may occur following a peri-implantitis will make the dental implants and the restorations performed on them to be closely monitored by both the medical team and the patient.

The transition from a minor emergency such as peri-implantitis to a major emergency such as septic complications in the vicinity of the maxillofacial areas can occur at any time. Ignorance is not an excuse as long as complications can be quite serious and can be prevented by simple procedures in regular check-ups.

\section{Acknowledgement}

In this article, all the authors have equal contribution with the first author.
3. Albrektsson T, Isidor F. Consensus report of session IV. In: Karring T, Lang NP (eds). Proceedings of the 1st European Workshop on Periodontology. Berlin: Quintessence, 1994:365-369.

4. Cristache CM. Periimplantita: factori de risc, etiologie, patogenie, prevenție și tratament.
In: Cristache CM, Tănase G Burlibașa M. Progrese în medicina dentară, vol. II. București: Ed. Ars Docendi, 2012:130-168.

5. Gall I.I. Asistența stomatologică. București: Ed. Didactică și Pedagogică, 1971.

6. Malița M, Marcov EC, Eftene $O$ et al. About the necessity and compulsoriness of 
emergency assistance in dental medicine (Part 2). Acta Medica Transilvanica. 2018;23(3):91-94.

7. Ionescu I, Eftene O, Ionescu $\mathrm{C}$ et al. About the necessity and compulsoriness of emergency assistance in dental medicine (Part 1). Acta Medica Transilvanica. 2018;23(2):79-82.

8. Sfeatcu R. Rolul profilaxiei în tratamentul cu ajutorul implanturilor dentare. In: Cristache CM, Tănase G Burlibașa M. Progrese în medicina dentară, vol. II. București: Ed. Ars Docendi, 2012:28-41.

9. Igienizarea profesională a implanturilor dentare. Instrumente și tehnici. In: Cristache CM, Tănase G Burlibașa M. Progrese în medicina dentară, vol. II. București: Ed. Ars Docendi, 2012:89-109.

10. Berglundh T, Armitage G, Araujo MG, Avila-Ortiz G, Blanco J, Camargo PM, Chen S, Cochran D, Derks J, Figuero E, Hämmerle CHF, Heitz-Mayfield LJA, Huynh-Ba G, lacono V, Koo KT, Lambert F, McCauley L, Quirynen M, Renvert S, Salvi GE, Schwarz F, Tarnow D, Tomasi C, Wang HL, Zitzmann N. Peri-implant diseases and conditions: Consensus report of workgroup 4 of the 2017 World Workshop on the Classification of Periodontal and PeriImplant Diseases and Conditions. J Clin Periodontol. 2018 Jun;45 Suppl 20:S286-S291.

11. Mombelli A, Lang NP. Antimicrobial treatment of peri-implant infections. Clin Oral Implants Res. 1992 Dec;3(4):162-8.

12. Corbella S, Del Fabbro M, Taschieri S, De Siena F, Francetti L. Clinical evaluation of an implant maintenance protocol for the prevention of peri-implant diseases in patients treated with immediately loaded full-arch rehabilitations. Int J Dent Hyg. 2011 Aug;9(3):216-22.

13. De Araújo Nobre M, Capelas C, Alves A, Almeida T, Carvalho R, Antunes E, Oliveira D, Cardador A, Maló P. Non-surgical treatment of peri-implant pathology. Int $\mathrm{J}$ Dent Hyg. 2006 May;4(2):84-90.

14. Monje A, Aranda L, Diaz KT et al. Impact of maintenance therapy for the prevention of peri-implant diseases: A systematic review and meta-analysis. J Dent Res. 2016;95(4):372-379.

15. Howe MS. Implant maintenance treatment and peri-implant health. Evid Based Dent. 2017 Mar;18(1):8-10.
16. Lang NP, Wilson TG, Corbet EF. Biological complications with dental implants: their prevention, diagnosis and treatment. Clin Oral Implants Res. 2000;11 Suppl 1:146-55.

17. Romandini M, Lima C, Pedrinaci I, Araoz A, Costanza Soldini M, Sanz M. Clinical signs, symptoms, perceptions, and impact on quality of life in patients suffering from peri-implant diseases: a universityrepresentative cross-sectional study. Clin Oral Implants Res. 2021 Jan;32(1):100-111.

18. Steiner C, Bottini GB, Gaggl A. Brain abscess caused by dental peri-implantitis. $\mathrm{Br}$ J Oral Maxillofac Surg. 2021;59(1):109-110.

19. Jemt T, Karouni M, Abitbol J et al. A retrospective study on 1592 consecutively performed operations in one private referral clinic. Part II: Peri-implantitis and implant failures. Clin Implant Dent Relat Res. 2017;19(3):413-422.

20. John V, Shin D, Marlow A, Hamada Y. Peri-implant bone loss and peri-implantitis: A report of three cases and review of the literature. Case Rep Dent. 2016;2016:2491714. 